\title{
UMA VISÃO SOBRE O PROBLEMA DE ALOCAÇÃO DE BERÇOS
}

\section{A VIEW OF THE BERTH ALLOCATION PROBLEM}

\author{
Vanina Macowski Durski Silva \\ Engenheira de Produção Agroindustrial e Mestranda em Engenharia de Produção \\ Universidade Federal de Santa Catarinta/CNPq \\ Programa de Pós Graduação em Engenharia de Produção \\ Rua Apeninos n 38, apto 303 - Florianópolis-SC-Brasil \\ (48) 8424-1089 - vaninadurski@gmail.com

\section{Antônio Sérgio Coelho} \\ Professor Doutor em Engenharia de Produção \\ Universidade Federal de Santa Catarina \\ Programa de Pós Graduação em Engenharia de Produção \\ R. Dep. Antônio Edu Vieira, 1304, Apto 102 B - Florianópolis-SC-Brasil \\ 048 3721-7058 - coelho@deps.ufsc.br
}

\begin{abstract}
RESUMO
O presente artigo visa analisar as pesquisas científicas já realizadas sobre um dos problemas existentes no serviço portuário. A maioria dos estudos dos portos foca a atenção nos problemas estratégicos e táticos e assim, o que existe é um grande volume de estudos de aplicações da pesquisa operacional sobre operações de contêineres. Como a maioria dos berços são operados por companhias de navegação particulares, poucos estudos têm sido conduzidos na alocação de berços. Portanto, o propósito principal deste trabalho é verificar as diferentes formas aplicadas na resolução do problema de alocação de berços, programação de atracação.
\end{abstract}

Palavras-chave: Portos; Alocação; Berços. 


\begin{abstract}
The purpose of this article is to verify the available scientific research in one of the prevalent problems associated with port services. Most of the studies about ports focus on strategic and tactical problems, thus, there exists a large volume of papers with operational research applications about container operations. Since the majority of the berths are managed and operated by private shipping companies, few studies have been conducted on berth allocation. Therefore, the main purpose of this article is to verify the different applied forms used in the resolution of the berth allocation problem, scheduling of berthing.
\end{abstract}

Key-words: Ports; Allocation; Berths.

\title{
1. INTRODUÇÃO
}

O sistema de transportes de um país tem uma função de promover a circulação em todos os recantos do território nacional (PEIXOTO, 1977). Segundo Peixoto (1977), é no porto que se movimentam cargas, consolidam-se e desconsolidam-se caixas, ocorrem os serviços da alfândega e a organização do transporte e assim, "o porto é visto como uma porta de entrada, uma abertura para a constituição de negócios, criando um amplo campo de oportunidades industriais e comerciais" (SILVA, 1999).

Conforme Silva (1999) os portos devem adotar uma nova função que é a de organizar e gerenciar fluxos contínuos, buscando otimizar a eficácia interna, visto como instrumento capaz de fazer circular fluxos de mercadorias cada vez maiores em um tempo cada vez menor, e com custos sempre mais baixos e competitivos.

Como se trata e um alto volume movimentado de carga, os portos modernos têm introduzido equipamentos computadorizados e automatizados, além de pontes rolantes, que operadas por um único homem dispensam o trabalho de centenas de estivadores, diminuindo o custo dos serviços de forma drástica, podendo dar agilidade na operação. A tabela 1 demonstra a movimentação de contêineres durante o ano de 1991 em alguns dos principais portos do mundo:

Tabela 1 - Movimentação de contêiner em 1991 (em milhões)

\begin{tabular}{|l|c|}
\hline País & Contêiner \\
\hline Hong Kong & 0,2 \\
\hline Brasil & 0,8 \\
\hline Cingapura & 6,3 \\
\hline Roterdã & 3,1 \\
\hline
\end{tabular}

Fonte: Silva (1999) 
Já nos portos nacionais, o sonho de competitividade dos produtos brasileiros há tempos sofre a ação de ineficiência gerencial, além de custos portuários exorbitantes, o que representa a perda de bilhões de dólares nas exportações, inviabilizando a movimentação de cargas.

Outro exemplo de que no Brasil as condições de atendimento portuário continuavam precárias é a diferença de valores cobrados pela movimentação de um único contêiner frente aos portos de Antuérpia e Roterdã:

Tabela 2 - Valor cobrado pela movimentação de 1 contêiner (em US\$)

\begin{tabular}{|l|c|}
\hline Portos & Preço \\
\hline Antuérpia & 107 \\
\hline Roterdã & 150 \\
\hline Santos e Rio de Janeiro & 600 \\
\hline
\end{tabular}

Fonte: Oliveira (2000)

Diante dos dados analisados, pode-se assimilar tal precariedade nos portos nacionais e o descaso dos setores responsáveis pela expansão das exportações, bem como pela modernização dos portos, incentivo à cabotagem e construção naval (OLIVEIRA, 2000). E assim, Silva (1999) resume em uma única palavra o que é necessário para a questão portuária: qualidade, ou seja, quem prestar o melhor serviço com o menor custo permanecerá no mercado.

É nesse cenário caótico que o presente trabalho se propõe a pesquisar e analisar um dos problemas existentes no sistema portuário, o Problema de Alocação de Berços, de forma a contribuir para a evolução dos estudos no setor de transportes.

\section{PROBLEMA DE ALOCAÇÃO DE BERÇOS}

A Confederação Nacional de Transportes (CNT) define berço como sendo o "espaço destinado ao navio em um cais no qual ele pode operar com segurança". De acordo com Nishimura, Imai e Papadimitriou (2001), em sua maioria, os berços nos grandes portos são arrendados, ou seja, alugados pelos operadores dos navios para o processamento de contêineres para alcançar maior produtividade. Enquanto isso é justificado no caso de uma rigorosa manipulação de um grande volume de contêineres com um grande número de navios aportando, isto pode não resultar em custos econômicos se estas quantidades não forem suficientes, pois parte do aumento dos custos é resultante da sobrecapitalização do porto para cargas de volumes, relativamente, pequenos. 
Neste contexto, é interessante limitar o número de berços operantes. A alocação de berços neste sistema, isto é, a atribuição de berços aos navios que aportam para a manipulação de cargas, torna-se importante na minimização do tempo de realização desta tarefa; devido o tempo de manipulação para um navio específico não ser necessariamente o mesmo para cada berço.

Conforme Paquette, Ashford e Wright (1982), a taxa de carregamento e descarga depende de: a) tipos de cargas; b) tipo de embarcação e tamanho (especialmente, o número de comportas);c) disponibilidade e tamanho da equipe de estivadores; d) grau de mecanização e métodos de manipulação de cargas.

Segundo Paquette, Ashford e Wright (1982) no planejamento dos portos, os engenheiros devem obter confiáveis previsões do número e tempo de distribuição da movimentação de navios na ordem de antecipar o número de berços requeridos.

Portanto, dimensões adequadas para canais e berços devem ser estipulados para permitir segurança, ativa movimentação dos navios e atracação; além disso, suficiente praça para manobra também deve ser estipulada para carregamento e descarregamento de navios e também para abastecimento e suprimento dos mesmos.

A profundidade do porto e a abordagem do canal devem ser suficientes para permitirem o completo carregamento de navios para navegar seguramente em águas profundas. Obviamente, a profundidade do porto requerida depende principalmente da distância vertical entre a linha da água e a quilha dos navios usando o porto.

A largura da entrada necessária naturalmente será influenciada pelo tamanho do porto e dos navios que o utilizam. Como regra, a largura da entrada deve ser aproximadamente igual ao comprimento do maior navio que utiliza tal porto.

Terminais que acomodam navio-tanque e outros navios de carga variam amplamente quanto ao berço e espaço requerido para atracação. Não existem padrões para berços e dimensionamento do porto, e os espaços vão depender também dos procedimentos de manipulação de cargas e equipamentos. O comprimento do berço deve ser igual ao comprimento do navio, mais um pequeno espaço entre os navios adjacentes e o espaço para as linhas dos navios. A forma e extensão da área do ancoradouro serão dependentes principalmente de alguns fatores: a) o número máximo de navios a serem atendidos; b) o tamanho dos navios; c) o método de atracação; d) necessidade de mobilidade; e) condições topográficas do local proposto.

Uma vez definidas as características físicas do terminal portuário, deve-se ter em mente que o mesmo deverá ser hábil para realizar no mínimo três funções principais conforme 
as orientações de Paquette, Ashford e Wright (1982): carregar/descarregar cargas de navios com eficiência e rapidez; prover adequado sistema, temporário e de longo prazo, de armazenagem para cargas que chegam e partem e, prover conexões, seja ferroviária ou rodoviária, para movimento do frete dentro e fora da área do porto.

Enquanto a capacidade prática do porto pode ser limitada por alguma dessas funções, a primeira é geralmente o fator de controle. Portanto, a capacidade de operação será essencialmente o produto da taxa de manipulação de cargas (t/dia/berço ocupado) e o número e o grau de utilização dos berços.

Assim, os gerentes na maioria dos portos buscam reduzir os custos através de uma eficiente utilização dos recursos incluindo recursos humanos, berços, área destinada aos contêineres, guindastes para movimentação dos contêineres e vários outros equipamentos. E, dentre todos estes recursos, os berços são os mais importantes recursos e um planejamento e agendamento dos berços melhora a satisfação dos consumidores e aumenta a movimentação nos portos, conduzindo a altos rendimentos no porto.

\subsection{O problema propriamente dito}

Conforme Guan e Cheung (2004) considera-se o problema de alocar espaço nos berços para navios em terminais portuários, como sendo o problema de alocação de berços. $\mathrm{Na}$ definição de Moon (2000) o problema consiste em determinar o momento da atracação e as posições de cada navio no terminal portuário.

O planejamento da atracação dos navios atribui embarcações da superfície a um berço antes de sua entrada no porto ou, reatribui navios que já estão no porto a realizar um avanço no treinamento de manutenção e eventos de certificação, os quais desenvolvem prontidão para futuras operações. Estes eventos incluem sistema de manutenção de combates, testes e treinamentos, dentre outros.

Uma vez que o plano de atracação está aprovado, mudanças são inevitáveis. De acordo com Brown, Cormican e Lawphongpanich (1997), requisição de mudanças para serviços, atrasos e chegadas antecipadas dos navios são eventos rotineiros e eles requerem revisões freqüentes no plano aprovado. Por ser alta a freqüência de revisões torna-se necessário um planejamento da alocação de berços computadorizados a fim de se evitar enganos e consequentemente, atrasos e custos provenientes destes (BROWN et al., 1994).

Devido o espaço dos berços ser muito limitado e milhares de contêineres ser manipulados diariamente, uma efetiva alocação de berços torna-se crítica para o eficiente 
gerenciamento do fluxo de tráfico de contêineres. Um típico berço de um terminal portuário pode acomodar múltiplos navios ao mesmo tempo (GUAN; CHEUNG, 2004). Quando não existe espaço disponível no berço, o navio precisa aguardar para atracar. Por simplicidade, Guan e Cheung (2004) denominam a soma do tempo de espera e o tempo de processamento (atendimento) de um navio como seu tempo de fluxo.

Conforme Moon (2000), cada navio requer uma quantidade específica de espaço no berço durante um pré-determinado período de tempo para descarregar e carregar contêineres. Neste processo, diversas variáveis devem ser consideradas, as quais incluem a duração e o momento de chegada de cada navio, o número de contêineres para descarregar e carregar, e a localização da estocagem de contêineres a serem carregados nos respectivos navios para deixarem o porto.

Brown et al. (1994) complementa as variáveis existentes sugerindo as limitações de comprimento do berço, profundidade no berço e força dos cabos utilizados. Nishimura, Imai e Papadimitriou (2001) faz um alerta para que o navio ao qual está se planejando a atracação não exceda a profundidade da água do berço ao qual foi atribuído.

Uma vez determinada as restrições as quais se deseja considerar, deve-se levar em conta que quando a taxa de chegadas de navios é alta ou quando chegadas inesperadas ocorrem, isso pode tornar impossível o término dos serviços para todos os navios no tempo previamente planejado. Assim, a partida de alguns navios pode ser atrasada. Neste caso, há operadores de terminais portuários que geralmente possuem diferentes prioridades para diferentes tipos de navios, onde pode haver penalizações de custo para os mesmos (KIM; MOON, 2003).

Contudo, a posição de atracação é também uma variável de decisão muito importante pelas seguintes razões. Os contêineres a serem carregados em navios geralmente chegam ao porto alguns dias antes da chegada dos navios no porto. Portanto, se um navio é atracado em uma localização próxima ao local de armazenagem dos contêineres a serem carregados no navio, o custo de entrega dos contêineres pelos caminhões ou outro equipamento de transporte interno no porto, pode ser minimizado.

De acordo com Kim e Moon (2003), algumas localizações de atracação podem ser preferidas sobre outras localizações devido aos fatores tais como contratos de longo período que especificam o uso dos berços com transportadores, o mínimo espaço requerido para um navio, diferentes níveis de ondas de acordo com as localizações no cais.

\section{LITERATURA RELACIONADA AO PROBLEMA DE ALOCAÇÃO DE BERÇOS}


Como citado anteriormente, a maioria dos estudos dos portos foca a atenção nos problemas estratégicos e táticos relacionados às operações de contêineres, havendo pouco conteúdo pesquisa sobre o específico problema de alocação de berços.

Brown et al. $(1994,1997)$ tratam o problema de alocação de berços em portos navais. Os autores identificam que o conjunto ótimo de atribuições navio-a-berço que maximiza a soma dos benefícios por navios enquanto no porto. O planejamento de berços em portos navais tem diferenças importantes de um planejamento de berços em portos comerciais. Segundo Imai, Nishimura e Papadimitriou (2001), nos portos navais a troca de berços ocorre para serviços próprios, ou seja, um novo navio que chega deve ser atribuído a um berço onde outro navio já esteja atracado. Este tratamento é improvável em portos comerciais. Deste modo, trocas de berços, bem como, outros fatores menos relevantes para portos comerciais são considerados em Brown et al., tornando o problema deles impróprio para portos comerciais.

Kim e Moon (2003) utilizaram a programação linear inteira para a resolução do problema com o auxílio do programa LINDO $^{\circledR}$. O tempo computacional do LINDO aumentava rapidamente quando o número de navios se tornava maior que 7 e o horizonte de planejamento excedia 72 horas. Assim, chegou-se à conclusão de que era inviável resolver o problema através de um modelo inteiro linear e um algoritmo de simulated annealing foi sugerido para o problema de alocação de berços e comparado com o desempenho da técnica de otimização. Em seguida, verificou-se que o algoritmo obteve resultados tão bons quanto à técnica utilizada anteriormente, porém ainda obteve vantagem quanto ao tempo computacional reduzido.

Nos estudos de Lim (1998) o problema foi transformado numa versão restrita do problema bidimensional de empacotamento e foi apresentado um grafo que demonstrou o problema sucintamente. Em sua forma de resolução, considerou-se o momento de atracação como sendo fixo, tentando decidir as localizações de atracação.

Na pesquisa de Park e Kim (2003) foi proposto um método para programação dos berços e guindastes no terminal portuário. O método de resolução foi dividido em duas fases. $\mathrm{Na}$ primeira fase, o momento das atracações e as posições dos navios são determinados. $\mathrm{Na}$ segunda fase uma programação detalhada da operação dos guindastes individuais é construída. Na primeira fase, a técnica de otimização do subgradiente é aplicada, enquanto na segunda fase é aplicada a técnica da programação dinâmica. 
Guan e Cheung (2004) consideram duas formulações matemáticas com o objetivo de fluxo de tempo ponderado e, propõe um procedimento heurístico para resolver problemas grandes. Reúnem navios em grupos e assumem que os navios de um mesmo grupo chegam no mesmo horário. A abordagem é tática em sua natureza e não pode ser adaptada para programar navios em um cenário dinâmico.

Imai, Nishimura e Papadimitriou (2001) consideram o problema de alocação de berços para portos comerciais. Primeiramente trata-se do problema de alocação estática de berços (SBAP), que pode ser formulado como um problema de atribuição inteira tridimensional, considerando que todos os navios já estão no porto quando o planejamento de atracação é determinado. Posteriormente trata-se do problema de alocação dinâmica de berços (DBAP), isto é, quando todos os navios possuem seu horário de chegada adiantadamente, e não chegam ao porto antes dos berços ao quais serão alocados estarem disponíveis para a atracação.

A figura 1 exemplifica o SBAP onde está sendo considerado que há um berço disponível para atracação e três navios a serem alocados seguindo uma ordem de atendimento, no decorrer do tempo.

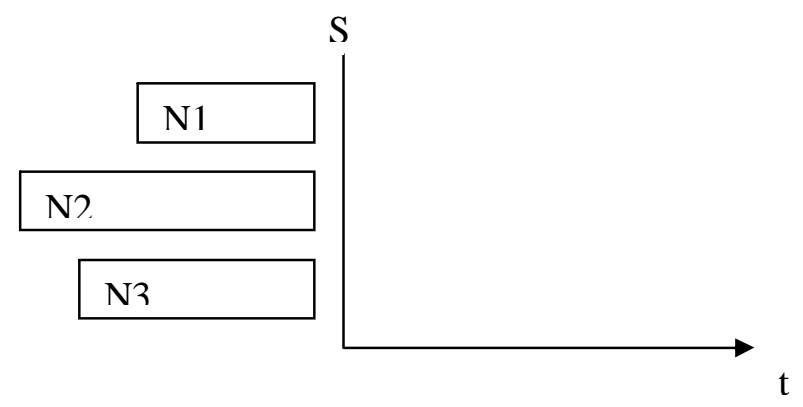

Figura 1: Exemplificação do SBAP

Fonte: do autor

Onde $S$ representa o momento em que o berço se torna disponível para se iniciar a programação de atendimento dos navios, $t$ indica o decorrer do tempo e $N$ representa o navio. Somente após a liberação do berço é que será feita a ordem de atendimento dos navios. Já para o caso do DBAP, a programação de alocação dos navios é feita em tempo real, ou seja, à medida que vão chegando os navios, o planejamento é reajustado indicando a posição de atendimento de um dado navio. A figura 2 ilustra este caso. 


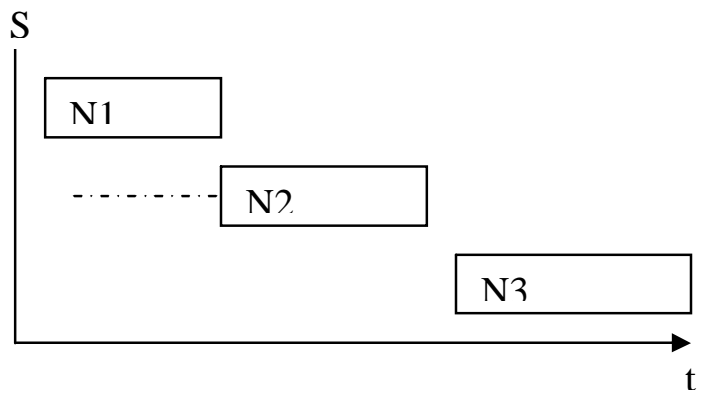

Figura 2: Exemplificação do DBAP

Fonte: do autor

Para o caso do DBAP, o berço é liberado e posteriormente, os navios vão chegando e sendo agendados para o atendimento. Note que devido o navio $\mathrm{N} 2$ ter chegado antes de o N1 ter concluído seu serviço, o N2 teve que esperar pelo atendimento; ao passo que após N2 terminar seu serviço, não havia nenhum outro navio no porto, havendo um tempo ocioso no berço até a chegada de N3.

Devido o DBAP ser do tipo de programação inteira mista sua resolução não ocorre em tempo polinomial. Assim, poderia ser resolvido pela técnica branch-and-bound (uma das mais utilizadas para encontrar a solução ótima de problemas de otimização NP-difíceis), porém consome muito tempo computacional. Deste modo, os autores deste artigo desenvolveram uma heurística utilizando a Relaxação Lagrangeana, com o método de otimização do subgradiente, cujo ganho no tempo computacional para grandes escalas é notável.

Nishimura, Imai e Papadimitriou (2001) propõem um modelo para o DBAP aplicando algoritmo genético com atendimento de múltiplos navios. Para isto empregam dois diferentes tipos de representações para os cromossomos (R1 e R2).

O comprimento dos dígitos do cromossomo R1 é definido pelo número de navios mais o número de berços menos um. Ele consiste de duas partes separadas com zero, cada uma representando uma fila de serviço para um dos dois berços. 


\begin{tabular}{cccccccccccc} 
Gene: Navio \# & \multicolumn{1}{c}{} & $\sim$ & 9, & 0 & (zero) & & & & \\
(Célula \#) & 1 & 2 & 3 & 4 & 5 & 6 & 7 & 8 & 9 & 10 \\
Cromossomo & 2 & 8 & 5 & 9 & 0 & 4 & 7 & 3 & 1 & 6 \\
Berço \# & 1 & 1 & 1 & 1 & & 2 & 2 & 2 & 2 & 2 \\
Ordem de serviço & 1 & 2 & 3 & 4 & & 1 & 2 & 3 & 4 & 5
\end{tabular}

Figura 3: R1

Fonte: Nishimura, Imai e Papadimitriou (2001)

O cromossomo R2 consiste também de duas partes cada qual com o comprimento fixo (o comprimento corresponde ao número total de navios a ser programados). Um gene, ou célula, que não estiver zerado indica um número do navio atribuído à correspondente ordem de seqüência de serviço, enquanto um gene zerado representa que nenhum navio foi atribuído.

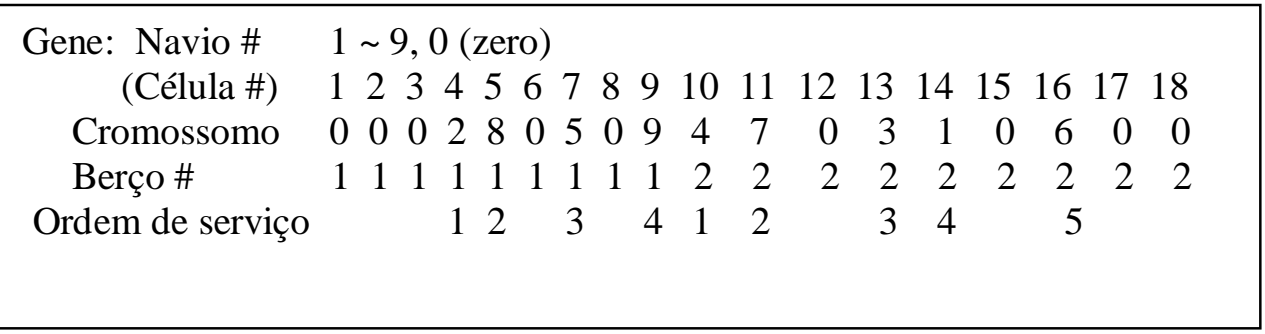

Figura 4: R2

Fonte: Nishimura, Imai e Papadimitriou (2001)

O problema de alocação de berços foi resolvido em três diferentes casos: considerando 5, 7 e 10 berços, com 25 e 50 navios. Entre os 2 esquemas de cromossomos não houve diferença significativa, exceto no problema 5 berços, 50 navios, onde R2 se comportou melhor que o R1.

Posteriormente, este trabalho foi comparado com o trabalho realizado por Imai, Nishimura e Papadimitriou (2001) onde chegou-se à seguinte conclusão: os resultados foram melhores com a aplicação do método da relaxação Lagrangeana embora as diferenças não sejam significativas. Anteriormente ao trabalho de Nishimura, Imai e Papadimitriou (2001), Chan et al. apud Nishimura, Imai e Papadimitriou (2001), haviam desenvolvido uma heurística baseada em algoritmo genético para o problema de alocação de berços com múltiplas restrições de atracação de navios relaxadas. 
Imai, Nagaiwa e Tat (1994) propuseram um algoritmo que minimiza a soma dos tempos de espera dos navios no porto e que minimiza a insatisfação dos navios em termos da ordem de atracação. O problema de alocação de berços inicialmente é formulado como um problema não linear inteiro multiobjetivo e para facilitar sua resolução é reformulado como um simples problema de atribuição.

Um dos trabalhos mais recentes publicado de Imai, Nishimura e Papadimitriou (2005) utiliza algumas suposições do trabalho de Imai, Nishimura e Papadimitriou (2001) além de considerar que o tempo de manipulação dos navios depende da localização no cais onde um navio em particular é atendido. Mais precisamente, é assumido que o tempo de manipulação é definido pelo relacionamento físico entre a posição do navio no cais e a localização da estocagem de seus contêineres no pátio.

Na resolução do problema de alocação de berços, os autores consideram o problema semelhante ao problema de corte de estoques, uma vez que há necessidade de se realizar cortes para se produzir pequenos pedaços de materiais, neste caso em retângulos, os quais representam os navios atracados nos berços. A figura 5 exemplifica este caso:

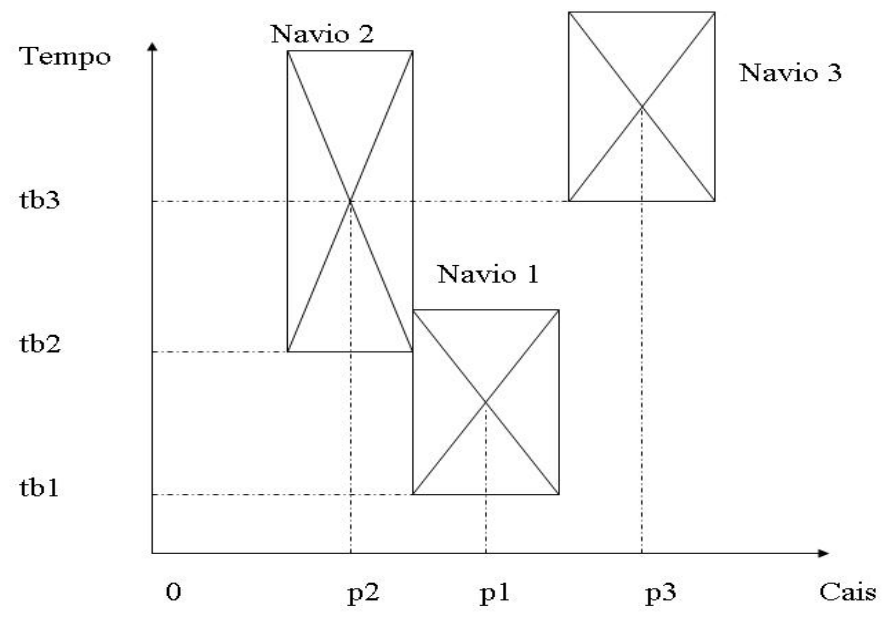

Figura 5 Representação gráfica da alocação de berços

Fonte: Imai et al. (2005)

Onde tbN representa o momento do início da manipulação de cada navio e pN representa a localização de cada navio no cais.

Para a resolução do problema um algoritmo heurístico foi desenvolvido e as conclusões obtidas foram de que para o problema de alocação de berço contínuo os resultados 
foram piores quando houve um aumento no número de navios e também o tempo médio de serviço foi pior para o problema contínuo quando o número de navios aumentava.

\section{CONSIDERAÇÕES FINAIS}

Nesta pesquisa foram apresentadas algumas das diferentes maneiras de se resolver o problema de alocação de berços, cada qual com sua particularidade, onde cada método considera diferentes variáveis de relevante importância para a definição do melhor berço a cada navio.

Diante de tais métodos encontrados os procedimentos desenvolvidos por Nishimura, Imai e Papadimitriou (2001) e Imai, Nishimura e Papadimitriou (2001) transpareceram os mais práticos e fáceis de se resolver.

O próximo passo desta pesquisa é levar em conta a prioridade de atendimento dos navios, o que não foi considerado em nenhum dos artigos já apresentados, mas que é de suma importância para os operadores portuários visando maior flexibilidade em suas decisões e provendo várias alternativas para atendimento de seus clientes.

Assim, espera-se ter contribuído para o incremento na literatura sobre o problema de alocação de berços e para os estudos de transportes de um modo geral. Para futuros trabalhos, um novo método de resolução com o conceito do problema do caixeiro viajante é recomendado.

\section{REFERÊNCIAS}

BROWN, Gerald G., LAWPHONGPANICH, Siriphong, THURMAN, Katie Podolak. Optimizing ship berthing. Naval Research Logistics, v. 41, p. 1-15, 1994. 
BROWN, Gerald G., CORMICAN, Kelly J., LAWPHONGPANICH, Siriphong, WIDDIS,

Daniel B. Optimizing submarine berthing with a persistence incentive. Naval Research Logistics, v. 44, 1997.

GUAN, Yongpei; CHEUNG, Raymond K. The berth allocation problem: models and solutions methods. OR Spectrum, v. 26, p. 75-92, 2004.

IMAI, Akio, NISHIMURA, Etsuko, PAPADIMITRIOU, Stratos. The dynamic berth allocation problem for a container port. Transportation Research Part B, v. 37, p. 401-417, 2001.

IMAI, Akio, NISHIMURA, Etsuko, PAPADIMITRIOU, Stratos. Berth allocation with service priority. Transportation Research Part B, v. 37, p. 437-457, 2003.

IMAI, Akio, SUN, Xin, NISHIMURA, Etsuko, PAPADIMITRIOU, Stratos. Berth allocation in a container port: using a continuous location space approach. Transportation Research Part B, v. 39, p. 199-221, 2005.

IMAI, Akio, NAGAIWA, Ken'Ichiro, TAT, Chan Weng. Efficient planning of berth allocation for container terminals in Asia. Journal fo Advanced Transportation, v. 31, n. 1, p.75-94, 1994.

KIM, Kap Hwan, MOON, Kyung Chan. Berth scheduling by simulated annealing. Transportation Research Part B, v. 37, p. 541-560, 2003.

LIM, Andrew. The berth planning problem. Operations Research Letters, v. 22, p. 105-110, 1998.

LOIOLA, E. M., ABREU, N. M. M. de, BOAVENTURA, P. O. N. Uma revisão comentada das abordagens do problema quadrático de alocação. Pesquisa Operacional, v. 24, n. 1, 2004

MOON, K. C. A mathematical model and a heuristic algorithm for berth planning. Brain Korea 21 Logistics Team, July, 2000. 
NISHIMURA, Etsuko, IMAI, Akio, PAPADIMITRIOU, Stratos. Berth allocation planning in the public berth system by genetic algorithms. European Journal of Operational Research, v. 131, p. 282-292, 2001.

OLIVEIRA, Carlos Tavares de. Modernização dos portos. 3. ed. São Paulo: Aduaneira, 2000.

PAQUETTE, Radnor J., ASHFORD, Norman J., WRIGHT, Paul H. Transportation engineering: planning and design. 2. ed. John Wiley \& Sons, Inc., 1982.

PARK, Young-Man, KIM, Kap Hwan. A Scheduling Method for Berth and Quay Cranes. OR Spectrum, v. 25, p. 1-23, 2003.

PEIXOTO, João Batista. Os transportes no atual desenvolvimento do Brasil. Rio de Janeiro: Biblioteca do Exército, 1977.

Pesquisa Aquaviária CNT 2006: Portos Marítimos: Longo curso e cabotagem. Confederação Nacional dos Transportes , Brasília, 2006.

SILVA, Gerardo. COCCO, Giuseppe. Cidade e portos: os espaços da globalização. Rio de Janeiro: DP\&A , 1999. 